\title{
Prevalence of glucose-6-phosphate dehydrogenase (G6PD) deficiency among malaria patients in Upper Myanmar
}

Jinyoung Lee ${ }^{1,5}$, Tae Im Kim ${ }^{1,6}$, Jung-Mi Kang ${ }^{1,2}$, Hojong Jun ${ }^{3}$, Hương Giang Lể,2, Thị Lam Thái 1,2, Woon-Mok Sohn ${ }^{1}$, Moe Kyaw Myint ${ }^{4}$, Khin Lin ${ }^{4}$, Tong-Soo Kim ${ }^{3 *}$ and Byoung-Kuk Na ${ }^{1,2^{*}}$

\begin{abstract}
Background: Glucose-6-phosphate dehydrogenase (G6PD; EC 1.1.1.49) deficiency is one of the most common X-linked recessive hereditary disorders in the world. Primaquine $(\mathrm{PQ})$ has been used for radical cure of $P$. vivax to prevent relapse. Recently, it is also used to reduce $P$. falciparum gametocyte carriage to block transmission. However, PQ metabolites oxidize hemoglobin and generate excessive reactive oxygen species which can trigger acute hemolytic anemia in malaria patients with inherited G6PD deficiency.
\end{abstract}

Methods: A total of 252 blood samples collected from malaria patients in Myanmar were used in this study. G6PD variant was analysed by a multiplex allele specific PCR kit, DiaPlexC ${ }^{\text {TM }}$ G6PD Genotyping Kit [Asian type]. The accuracy of the multiplex allele specific PCR was confirmed by sequencing analysis.

Results: Prevalence and distribution of G6PD variants in 252 malaria patients in Myanmar were analysed. Six different types of G6PD allelic variants were identified in 50 (7 females and 43 males) malaria patients. The predominant variant was Mahidol (68\%, 34/50), of which 91.2\% (31/34) and 8.8\% (3/34) were males and females, respectively. Other G6PD variants including Kaiping (18\%, 9/50), Viangchan (6\%, 3/50), Mediterranean (4\%, 2/50), Union (2\%, 1/50) and Canton $(2 \%, 1 / 50)$ were also observed.

Conclusions: Results of this study suggest that more concern for proper and safe use of $\mathrm{PQ}$ as a radical cure of malaria in Myanmar is needed by combining G6PD deficiency test before PQ prescription. Establishment of a follow-up system to monitor potential $\mathrm{PQ}$ toxicity in malaria patients who are given $\mathrm{PQ}$ is also required.

Keywords: Glucose-6-phosphate dehydrogenase (G6PD), G6PD deficiency, Malaria, Primaquine, Myanmar

\section{Background}

Glucose-6-phosphate dehydrogenase (G6PD; EC 1.1.1.49) is an enzyme that maintains redox equilibrium in cells by catalyzing the first reaction in the pentose phosphate pathway. This pathway is the single source to supply reduced nicotinamide adenine dinucleotide phosphate (NADPH) which confers primary oxidative defense in red blood cells (RBCs). Therefore, G6PD activity is crucial to

\footnotetext{
* Correspondence: tongsookim@inha.ac.kr; bkna@gnu.ac.kr

${ }^{3}$ Department of Tropical Medicine, and Inha Research Institute for Medical Sciences, Inha University College of Medicine, Incheon 22212, Republic of Korea

${ }^{1}$ Department of Parasitology and Tropical Medicine, and Institute of Health Sciences, Gyeongsang National University College of Medicine, Jinju 52727, Republic of Korea

Full list of author information is available at the end of the article
}

protect $\mathrm{RBCs}$ from oxidative stresses induced by free radicals derived from oxygen and organic compounds such as drugs and their metabolites [1]. G6PD is encoded by G6PD gene that spans $18 \mathrm{~kb}$ on the $\mathrm{X}$ chromosome (Xq28), consisting of 13 exons separated by 12 introns [2]. Point mutations of this gene result in different levels of G6PD activity, consequently causing a diverse range of biochemical and clinical phenotypes [1]. More than 400 G6PD variants have been identified up to date, of which 186 variants are linked to G6PD deficiency by decreasing the activity or stability of G6PD [1, 3, 4]. Clinical manifestations caused by these G6PD variants vary from severe to asymptomatic and G6PD deficiency can be usually assessed by enzymatic and/or genetic assays. 
G6PD deficiency is one of the most common Xlinked recessive hereditary disorders in the world. It is characterized by abnormally low levels of G6PD $[5,6]$. G6PD deficient RBCs are more vulnerable to damages caused by oxidative stresses induced by foods and drugs, leading to acute hemolytic anemia (AHA) [7]. Most individuals with G6PD deficiency are clinically asymptomatic, but some G6PD variants could be lethal due to complete loss of enzyme activity. G6PD deficiency has been recognized as a good example of natural selection since strong geographic correlation of G6PD deficiency distribution with historical endemicity patterns of malaria has been identified [8-11]. G6PD deficiency provides resistance against severe malaria [12-15]. The precise mechanism of G6PD deficiency for protective effect against severe malaria is not fully understood, but it is likely to be associated with the effects of G6PD deficiency on RBC physiology. Optimum redox status in $\mathrm{RBCs}$ is essentially required by malaria parasites for their survival and development in RBCs. Inability to maintain normal redox status in G6PD deficient RBCs results in oxidative stress that may unfavorable to malaria parasites, which supporting the protection hypothesis [13]. But paradoxically, G6PD deficiency is also a stumbling block in fighting against malaria. Primaquine (PQ) has been used for radical cure of Plasmodium vivax to prevent relapse. It is recently being used to reduce $P$. falciparum gametocyte carriage to block transmission. However, PQ metabolites can oxidize hemoglobin and generate excessive reactive oxygen species which can cause lethal AHA in malaria patients with inherited G6PD deficiency $[16,17]$. Due to this reason, the WHO recommends G6PD test prior to administration of $\mathrm{PQ}$ for radical cure of $P$. vivax [18]. PQ has been widely used in Myanmar for radical cure of $P$. vivax and $P$. ovale. Using single dose PQ as a gametocytocide for P. falciparum is also recommended. However, diagnosis of G6PD status in malaria patients before PQ prescription is not generally conducted in the country. Information on G6PD deficiency and potential risk of PQ by the genetic disorder in malaria patients are also lacking.

Several studies have reported the prevalence of G6PD deficiency and its variants in Myanmar population [19-23]. However, the status of G6PD deficiency in malaria patients has not been reported in the literature. The aim of this study was to determine the prevalence of G6PD deficiency in confirmed malaria patients in Upper Myanmar. A total of 50 out of 252 enrolled malaria patients were determined to have G6PD deficiency with several different genetic variants. Our results strongly suggest the necessity to monitor the presence of G6PD deficiency in Myanmar malaria patients before prescribing $\mathrm{PQ}$.

\section{Methods}

\section{Blood samples}

A total of 252 blood samples were used in this study (Table 1). These blood samples were collected from malaria patients who attended public health centers in Naung Cho, Pyin Oo Lwin, Tha Beik Kyin townships, and Mandalay in Upper Myanmar from August 2013 to December 2015. The average age of these 252 subjects was 27.8 years (range, 14-53 years). Malaria infections were confirmed by microscopic examination and species-specific nested polymerase chain reaction (PCR) [24]. Informed written consent was obtained from each enrolled patient prior to blood sampling. Two or three drops of blood (approximately $50 \mu \mathrm{l}$ ) from a finger prick were blotted onto Whatman $3 \mathrm{MM}$ filter paper (GE Healthcare, Maidstone, UK) and allowed to air dry. This study was approved by the Ethics Review Committee, Department of Medical Research, Myanmar (1/Ethics/ DMRUM/2013 and 97/Ethics 2015) and by the Ethical Review Committee of Inha University School of Medicine, Korea (INHA 15-013).

\section{G6PD multiplex allele specific PCR}

Genomic DNA was extracted from Plasmodium-positive blood filters using QIAamp DNA Blood Mini Kit (Qiagen, Hilden, Germany) according to the manufacturer's protocols. G6PD variants were screened using a multiplex allele specific PCR kit, DiaPlexC $C^{\mathrm{m}}$ G6PD Genotyping Kit [Asian type] (SolGent, Daejeon, Korea). This kit can detect eight different G6PD variants: Vanua Lava (383 T > C, 154 bp), Mahidol (487 G > A, 337 bp), Mediterranean (563 C> T, 262 bp), Coimbra (592 C> T, 243 bp), Viangchan (871 G>A, 501 bp), Union (1360 C > T, 803 bp), Canton (1376 G > T, 681 bp), and Kaiping (1388 G > A, 557 bp). Multiplex PCR was performed in a $25 \mu \mathrm{l}$ reaction containing $3 \mu \mathrm{l}$ of genomic DNA (approximately $20 \mathrm{ng}$ ), $12.5 \mu \mathrm{l}$ of $2 \times$ multiplex PCR Smart mix, $2 \mu \mathrm{l}$ of primer mixture and $7.5 \mu \mathrm{l}$ of distilled water. Amplification was performed with a denaturation at $95^{\circ}$ $\mathrm{C}$ for $15 \mathrm{~min}$ followed by amplification steps of 35 cycles $\left(95{ }^{\circ} \mathrm{C}\right.$ for $30 \mathrm{~s}, 60{ }^{\circ} \mathrm{C}$ for $30 \mathrm{~s}$ and $72{ }^{\circ} \mathrm{C}$ for $40 \mathrm{~s}$ ) and a final extension at $72{ }^{\circ} \mathrm{C}$ for $5 \mathrm{~min}$. Each amplicon was analyzed on $3 \%$ agarose gel to check size of amplified PCR product. Each reaction was confirmed with an internal control (wild type G6PD control, 1234 bp) following the protocols provided by the manufacturer.

Table 1 Blood samples from malaria patients used in this study

\begin{tabular}{lllll}
\hline & P. falciparum & P. vivax & P. falciparum + P. vivax & Total \\
\hline Male & 92 & 85 & 38 & 215 \\
Female & 14 & 14 & 9 & 37 \\
Total & 106 & 99 & 47 & 252 \\
\hline
\end{tabular}


Cloning and DNA sequencing analysis of G6PD variants To confirm the accuracy of the multiplex allele specific PCR and clarify if there were any other mutations besides the ones identified by the PCR method, samples for each variant detected by the multiplex method were randomly selected and subjected to nucleotide sequencing analysis. Variant regions corresponding to exon 6 , exon 9, exon 11, and exon 12 of G6PD gene were amplified from each genomic DNA using primers described previously [25]. To minimize nucleotide mismatch in sequences during PCR amplification, Ex Taq DNA polymerase (Takara, Otsu, Japan) with proofreading activity was used for all PCR procedures. Each PCR product was cloned into T\&A cloning vector (Real Biotech Corporation, Banqiao City, Taiwan) and transformed into Escherichia coli DH5 $\alpha$ competent cells. Positive clones with appropriate insert were selected. Nucleotide sequences of cloned G6PD regions were determined by automatic DNA sequencing. At least two or three clones from each sample were sequenced to ensure sequencing accuracy. These obtained nucleotide sequences were then analyzed using EditSeq and SeqMan in DNASTAR package (DNASTAR, Madison, WI, USA).

\section{Results}

A total of 252 blood samples from Myanmar malaria patients were analyzed to estimate the frequency of G6PD deficiency and its variants in these patients. The G6PD multiplex allele specific PCR analysis of 252 blood samples revealed several types of G6PD variants in $50 \mathrm{mal}-$ aria patients (Fig. 1). Although several weak non-specific amplification products were observed in some blood samples, amplification products were well corresponded to one of G6PD variants in the 50 blood samples. To determine whether these were non-specifically amplified products or real G6PD variants, variant regions of G6PD gene were amplified from the 50 samples and subsequently sequenced. Sequencing analyses confirmed that all 50 samples had corresponding G6PD variants consistent with multiplex allele specific PCR results (Fig. 2). Multiplex allele specific PCR and sequencing analysis revealed six different G6PD allelic variants in the 50 blood samples. Mahidol variant $(68 \%, 34 / 50)$ was the most common G6PD mutation identified, followed by Kaiping $(18 \%, 9 / 50)$, Viangchan $(6 \%, 3 / 50)$, Mediterranean $(4 \%, 2 / 50)$, Union $(2 \%, 1 / 50)$, and Canton $(2 \%, 1 /$ 50) variants. Coimbra or Vanua Lava G6PD variant was not detected. The overall frequency of G6PD deficiency was approximately $19.9 \%(50 / 252)$, among which $20.0 \%$ $(43 / 215)$ and $18.9 \%$ (7/37) were males and females, respectively (Table 2). Of these 50 malaria patients with G6PD variants, 25 (50.0\%), 17 (34.0\%), and 8 (16.0\%) were infected with $P$. falciparum, $P$. vivax, and co-infections with both $P$. falciparum and $P$. vivax, respectively.

\section{Discussion}

Although estimated malaria cases have declined remarkably in recent years, Myanmar still has the greatest malaria incidence in the Greater Mekong Region [17]. About $60 \%$ of the population (more than 30 million people) resides in malaria endemic areas. More than 350,000 confirmed malaria cases were reported in

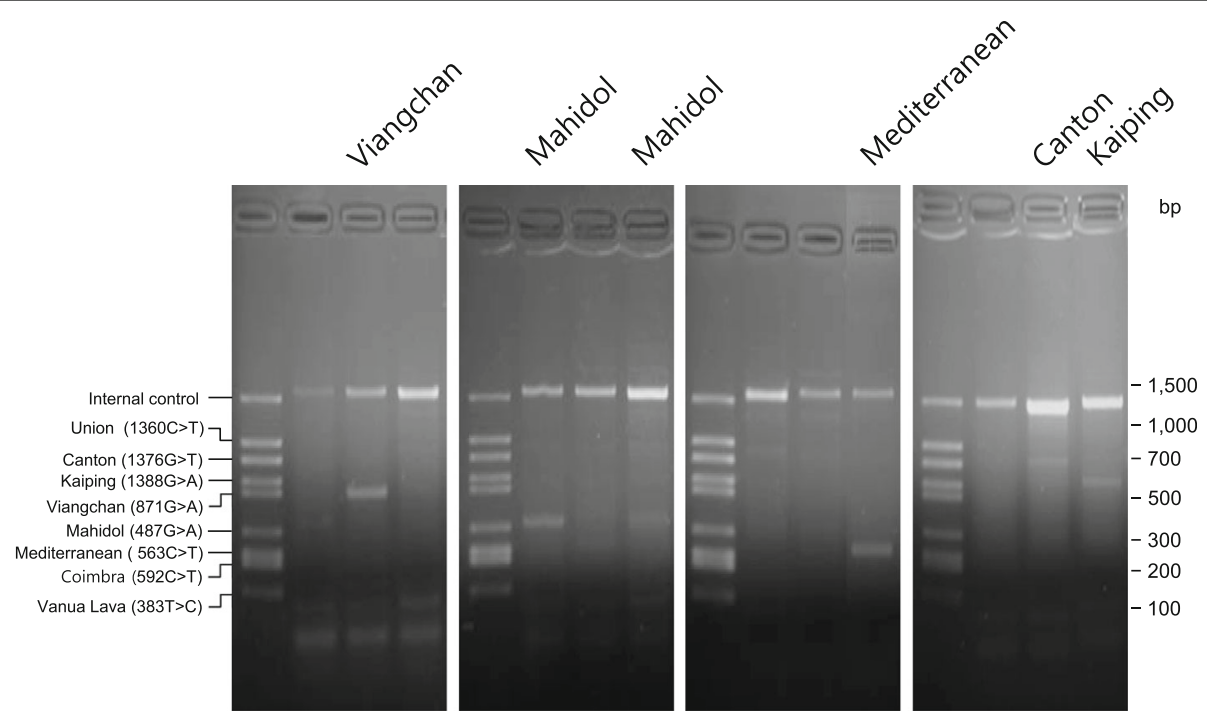

Fig. 1 G6PD multiplex allele specific PCR. G6PD variants in 252 Myanmar malaria patients were analyzed by multiplex allele specific PCR. Six different types of G6PD variants were identified in 50 malaria patients (19.8\%): Mahidol (487 G > A, 337 bp), Mediterranean (563 C > T, 262 bp), Viangchan (871 G > A, 501 bp), Union (1360 C > T, 803 bp), Canton (1376 G > T, 681 bp) and Kaiping (1388 G > A, 557 bp). Representative PCR results for G6PD variants are presented. Each PCR reaction was confirmed by an internal control (wild type G6PD control, 1234 bp) following the manufacturer's instruction. The results presented in this figure were obtained in male malaria patients except for Canton 


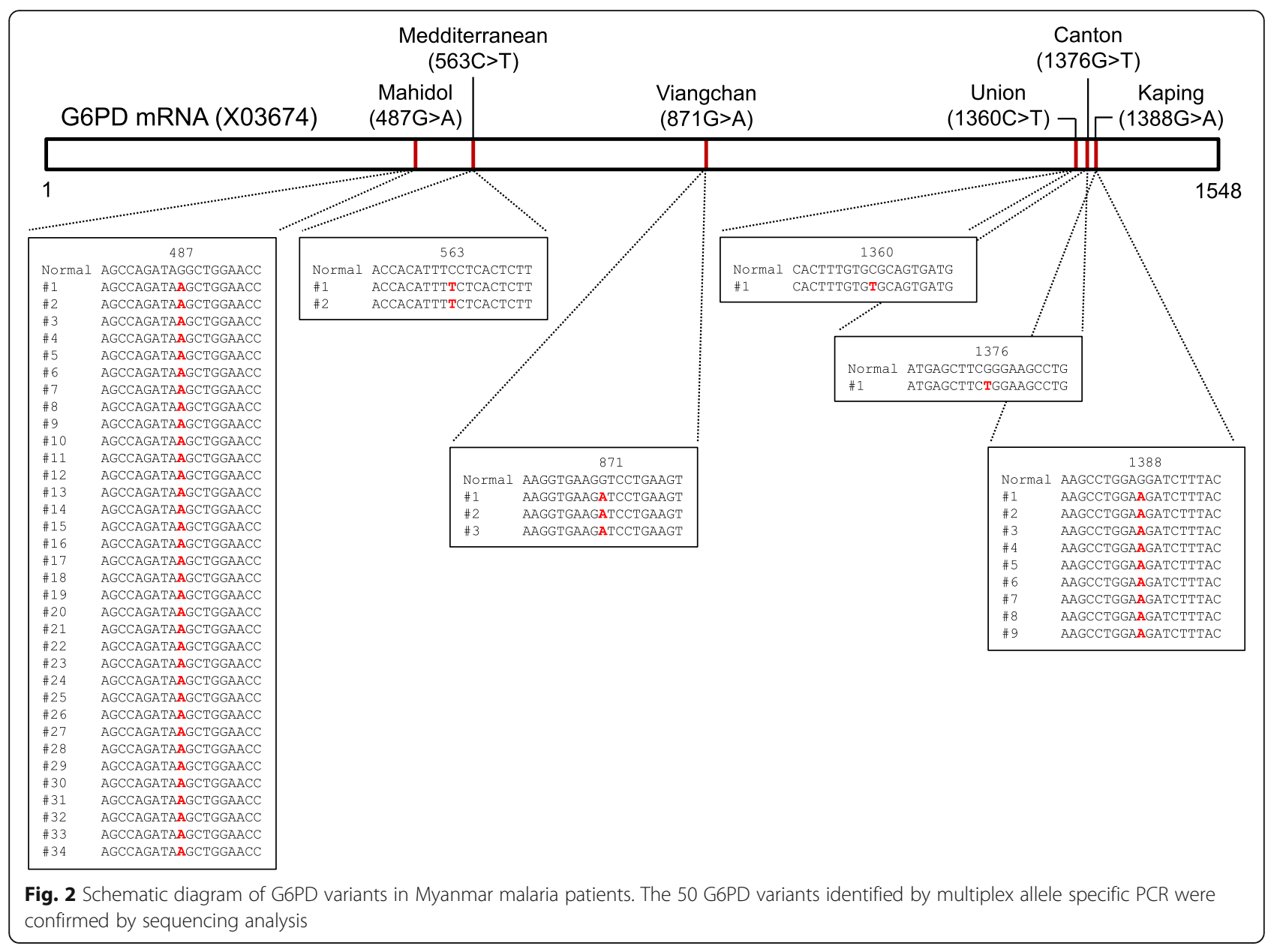

Table 2 Frequency of G6PD deficiency and G6PD variants in Myanmar malaria patients

\begin{tabular}{|c|c|c|c|c|c|}
\hline & Amino acid substitution & WHO classification ${ }^{a}$ & Female & Male & Total (\%) \\
\hline Normal & & & 30 & 172 & $202(80.1)$ \\
\hline G6PD deficiency & & & 7 & 43 & $50(19.9)$ \\
\hline Vanua Lava (383T>C) & L128P & $\|$ & 0 & 0 & $0(0.0)$ \\
\hline $\begin{array}{l}\text { Mahidol } \\
(487 G>A)\end{array}$ & G163S & III & 3 & 31 & $34(13.5)$ \\
\hline Mediterranean $(563 C>T)$ & $\mathrm{S} 188 \mathrm{~F}$ & $\|$ & 1 & 1 & $2(0.8)$ \\
\hline $\begin{array}{l}\text { Coimbra } \\
(592 \mathrm{C}>\mathrm{T})\end{array}$ & R198C & $\|$ & 0 & 0 & $0(0.0)$ \\
\hline $\begin{array}{l}\text { Viangchan } \\
(871 \mathrm{G}>\mathrm{A})\end{array}$ & V291M & III & 0 & 3 & $3(1.2)$ \\
\hline $\begin{array}{l}\text { Union } \\
(1360 C>T)\end{array}$ & $\mathrm{R} 454 \mathrm{C}$ & $\|$ & 0 & 1 & $1(0.4)$ \\
\hline $\begin{array}{l}\text { Canton } \\
(1376 G>T)\end{array}$ & R459L & III & 1 & 0 & $1(0.4)$ \\
\hline $\begin{array}{l}\text { Kaiping } \\
(1388 G>A)\end{array}$ & $\mathrm{R} 463 \mathrm{H}$ & $\|$ & 2 & 7 & $9(3.6)$ \\
\hline
\end{tabular}

${ }^{a}$ Class I, severe deficiency ( $<10 \%$ activity) with chronic (nonspherocytic) hemolytic anemia; class II, severe deficiency ( $<10 \%$ activity) with intermittent hemolysis severe deficiency; class III, mild deficiency (10-60\% activity) hemolysis with stressors only; class IV, non-deficient, variant, no clinical sequelae (50-150\% activity); Class V: Increased enzyme activity, no clinical sequelae (150>\% activity) 
Myanmar in 2013 [17]. Malaria patients usually receive anti-malaria drugs for treatment in public health care facilities or private sectors. However, G6PD deficiency has not been generally checked for patients. PQ is an antimalaria drug commonly prescribed either for antirelapsing vivax malaria or for blocking falciparum malaria transmission in Myanmar. However, it can trigger lifethreatening acute hemolytic complications in G6PD deficiency individuals. Therefore, information on G6PD deficiency status in malaria patients would be necessary for the establishment of a national malaria control program in Myanmar on anti-malaria drug policy and further research on the safety of PQ.

Fifty out of 252 malaria patients (215 males and 37 females) analyzed in this study had at least one of G6PD variants. Mahidol variant (68\%) was the most common G6PD variant identified followed by Kaiping (18\%), Viangchan (6\%), Mediterranean (4\%), Union (2\%), and Canton (2\%) variants. This result agreed with previous studies on G6PD variants in Myanmar showing that G6PD Mahidol was the most common G6PD variant type, even though the prevalence of G6PD variants among Myanmar population varied in different regions of the country according to ethnic variation $[19,20,22]$. The overall percentage of $P$. falciparum infected individuals with G6PD variants $(25 / 50,50.0 \%)$ and $P$. falciparum infected individuals with non-G6PD variants (81/ 202, 40.1\%) did not differ significantly. When including $P$. vivax mixed infection cases, $P$. falciparum infection rate in individuals with G6PD variants was $66.0 \%$ (33/ 50) while $P$. falciparum infection rate in those with nonG6PD variants was $59.4 \%(120 / 202)$. This result is consistent with a previous report showing that G6PD deficiency may not effectively protect patients against $P$. falciparum infection [26]. Interestingly, no significant association was observed between gender and G6PD variant status in patients with malaria. The frequency of G6PD variants in male $(43 / 215,20.0 \%)$ was similar to that in female $(7 / 37,18.9 \%)$. G6PD deficiency is an Xlinked hereditary disease. Therefore, males are usually affected more frequently than females as males only have one X-chromosome $[26,27]$. It has been proposed that G6PD variants render males substantial protection against severe malaria [15]. The number of female malaria patients enrolled in this study was smaller than that of males. However, when the incidence of G6PD variants in females was predicted by Hardy-Weinberg model, the estimated value accounted for about $36 \%$. Analysis of the effect of G6PD variant or deficiency on disease severity would be highly interesting. However, all patients enrolled in this study were uncomplicated cases with only typical malaria symptoms. Therefore, it was unable to clearly estimate the direct association between G6PD deficiency and the degree of severity.
This study has another limitation in that G6PD enzyme activity in malaria patients could not be checked due to technical limitation in performing enzyme assay in the field using fresh blood samples. Diagnosis of G6PD deficiency based on enzyme activity is usually cumbersome. Routine laboratory assays including spectrophotometry assay [28] and cytochemical staining assay [29] are not suitable for point-of-care test since these methods require well-equipped laboratories and trained technicians. Fluorescent spot test (FST) is the most widely used alternative assay for G6PD deficiency due to its simplicity and low cost [30]. In this study, FST assay was performed for dried blood filters. However, no reliable results were obtained probably due to poor quality of blood samples which might be due to inadequate storage and transport process. It is known that G6PD activity is influenced by the mutation position occurred in the gene. Correlations between clinical phenotypes and altered G6PD activity due to mutations have been well studied [31-35]. Based on the level of enzyme activity, World Health Organization has classified G6PD variants into five classes: Class I, severe deficiency of the enzyme with chronic non-spherocytic hemolytic anemia; Class II, severe deficiency with enzyme activity $<10 \%$ of normal; Class III, moderate deficiency with enzyme activity $10-60 \%$ of normal; Class $I V$, very mild to none deficiency with enzyme activity $60-100 \%$ of normal; and Class $V$, increased enzyme activity [36]. Among variants detected in this study, Union, Mediterranean, and Kaiping are classified as Class II variants while Mahidol, Viangchan, and Canton are classified as Class III variants [37]. Clinical impact of anti-malaria drugs other than PQ in individuals with different G6PD variants is currently unclear. However, G6PD genotype or phenotype is unlikely to influence the anti-malarial efficacy of other anti-malaria drugs, including combination therapy with artemisinin-based drugs [38, 39]. There is no evidence that PQ shows different pharmacokinetics between normal malaria patients and G6PD deficiency malaria patients [40]. A single dose of PQ $45 \mathrm{mg}$ and/or weekly for eight weeks has been routinely used to treat patients with $P$. falciparum gametocytes and/or $P$. vivax in Myanmar, ignoring G6PD deficiency. However, considering individuals with Class II or III G6PD deficiency have potential risk associated with clinically significant AHA during treatment with $\mathrm{PQ}$, results of this study suggest that more caution is needed when prescribing $\mathrm{PQ}$ and other 8-aminoquinoline based anti-malaria drugs for malaria patients. It is also worthy to mention that only several major Asian type G6PD variants are screened in this study. However, considering some G6PD variants are linked to other mutations including silence mutations in the G6PD gene [41-43], more systematic analysis of G6PD variants in a larger number of blood samples from malaria patients is needed for in-depth 
understanding of G6PD deficiency status in Myanmar malaria patients. Nonetheless, results of this study provide valuable information on G6PD deficiency status in malaria patients in Myanmar.

\section{Conclusions}

This study is the first report on the frequency of G6PD deficiency associated with malaria in Myanmar. The overall frequency of G6PD deficiency obtained in this study was similar to or slightly higher than the average expected frequencies for the Myanmar population $[19,20,22] . P$. falciparum and $P$. vivax accounted for most of malaria cases in areas where this study was performed. However, it is likely that $P$. vivax is becoming predominant species in these areas with recent decrease of falciparum malaria cases [24]. Therefore, proper and safe use of $\mathrm{PQ}$ as a radical cure of $P$. vivax combining with G6PD deficiency test is needed. Establishment of follow-up system to monitor possible PQ toxicity in malaria patients who are taking PQ is also required. Recently, availability of G6PD rapid diagnostic tests (RDT) has been suggested for point-of-care detection of G6PD deficiency in the field [23, 44-49]. RDT can be a promising option for G6PD deficiency screening tool prior to prescribe PQ or other 8-aminoquinoline based antimalaria drugs that can trigger AHA.

\section{Abbreviations}

AHA: Acute hemolytic anemia; FST: Fluorescent spot test; G6PD: Glucose-6phosphate dehydrogenase; NADPH: Nicotinamide adenine dinucleotide phosphate; PCR: Polymerase chain reaction; PQ: Primaquine; RBCs: Red blood cells; RDT: Rapid diagnostic tests

\section{Acknowledgements}

We thank the staffs in Department of Medical Research Pyin Oo Lwin Branch and the health professionals in Naung Cho, Pyin Oo Lwin and Tha Beik Kyin townships for their contribution and technical support in field study. This work was supported by the National Research Foundation of Korea (NRF) grants funded by the Korea government (MEST) (NRF-2017M3A9B8069530) and the Korea government (MSIP) (NRF-2015R1A2A2A01004310).

\section{Funding}

This work was supported by the National Research Foundation of Korea (NRF) grants funded by the Korea government (MEST) (NRF-2017M3A9B8069530) and the Korea government (MSIP) (NRF-2015R1A2A2A01004310).

\section{Availability of data and materials}

The original datasets analysed during the current study are available from the corresponding author upon request.

\section{Authors' contributions \\ $J$, TIK, JMK, LHG and TTL carried out analysis. HJ, MKM and KL collected blood samples from malaria patients. JL, TIK, JMK, WMS, KL, TSK and BKN analysed and interpreted the data. TSK and BKN designed and supervised the experiments. JL, TIK and BKN wrote the draft of the manuscript. All authors read and approved the final manuscript.}

\section{Ethics approval and consent to participate}

This study was approved by the Ethics Review Committee, Department of Medical Research, Myanmar (1/Ethics/DMRUM/2013 and 97/Ethics 2015), and by the Ethical Review Committee of Inha University School of Medicine, Korea (INHA 15-013). Informed written consent was obtained from each patient.
Consent for publication

Not applicable.

\section{Competing interests}

The authors declare that they have no competing interests.

\section{Publisher's Note}

Springer Nature remains neutral with regard to jurisdictional claims in published maps and institutional affiliations.

\section{Author details}

${ }^{1}$ Department of Parasitology and Tropical Medicine, and Institute of Health Sciences, Gyeongsang National University College of Medicine, Jinju 52727. Republic of Korea. ${ }^{2}$ BK21Plus Team for Anti-aging Biotechnology and Industry, Department of Convergence Medical Science, Gyeongsang National University, Jinju 52727, Republic of Korea. ${ }^{3}$ Department of Tropical Medicine, and Inha Research Institute for Medical Sciences, Inha University College of Medicine, Incheon 22212, Republic of Korea. ${ }^{4}$ Department of Medical Research Pyin Oo Lwin Branch, Pyin Oo Lwin, Myanmar. ${ }^{5}$ Present address: Department of Tropical Medicine, and Inha Research Institute for Medical Sciences, Inha University College of Medicine, Incheon 22212, Republic of Korea. ${ }^{6}$ Present address: Planning and Management Division, Nakdonggang National Institute of Biological Resources, Sangju 37242, Republic of Korea.

Received: 4 September 2017 Accepted: 1 March 2018

Published online: 16 March 2018

\section{References}

1. Cappellini MD, Fiorelli G. Glucose-6-phosphate dehydrogenase deficiency. Lancet. 2008;371:64-74.

2. Chen EY, Cheng A, Lee A, Kuang WJ, Hillier L, Green P, Schlessinger D, Ciccodicola A, D'Urso M. Sequence of human glucose-6-phosphate dehydrogenase cloned plasmids and a yeast artificial chromosome. Genomics. 1991:10:792-800.

3. Beutler E, Vulliamy T. Hematologically important mutations: glucose-6phosphate dehydrogenase. Blood Cells Mol Dis. 2002:28:93-103.

4. Minucci A, Moradkhani K, Hwang MJ, Zuppi C, Giardina B, Capoluongo E. Glucose-6-phosphate dehydrogenase (G6PD) mutations database: review of the "old" and update of the new mutations. Blood Cells Mol Dis. 2012;48:154-65.

5. Beutler E. Glucose-6-phosphate dehydrogenase deficiency. N Engl J Med. 1991:324:169-74.

6. Beutler E. G6PD deficiency. Blood. 1994;84:3613-36.

7. Howes RE, Battle KE, Satyagraha AW, Baird JK, Hay SI. G6PD deficiency: global distribution, genetic variants and primaquine therapy. Adv Parasitol. 2013:81:133-201.

8. Ruwende C, Khoo SC, Snow RW, Yates SN, Kwiatkowski D, Gupta S, Warn P, Allsopp CE, Gilbert SC, Peschu N, Newbold Cl, Greenwood BM, Marsh K, Hill AV. Natural selection of hemi- and heterozygotes for G6PD deficiency in Africa by resistance to severe malaria. Nature. 1995;376:246-9.

9. Ruwende C, Hill A. Glucose-6-phosphate dehydrogenase deficiency and malaria. J Mol Med (Berl). 1998;76(8):581.

10. Howes RE, Piel FB, Patil AP, Nyangiri OA, Gething PW, Dewi M, Hogg MM, Battle KE, Padilla CD, Baird JK, Hay SI. G6PD deficiency prevalence and estimates of affected populations in malaria endemic countries: a geostatistical model-based map. PLoS Med. 2012;911:e1001339.

11. Louicharoen C, Patin E, Paul R, Nuchprayoon I, Witoonpanich B, Peerapittayamongkol C, Casademont I, Sura T, Laird NM, Singhasivanon P, Quintana-Murci L, Sakuntabhai A. Positively selected G6PD-Mahidol mutation reduces Plasmodium vivax density in southeast Asians. Science. 2009;326:1546-9.

12. Bienzle U, Ayeni O, Lucas AO, Luzzatto L. Glucose-6-phosphate dehydrogenase and malaria. Greater resistance of females heterozygous for enzyme deficiency and of males with non-deficient variant. Lancet. 1972;1:107-10.

13. Tishkoff SA, Varkonyi R, Cahinhinan N, Abbes S, Argyropoulos G, Destro-Bisol G, Drousiotou A, Dangerfield B, Lefranc G, Loiselet J, Piro A, Stoneking M, Tagarelli A, Tagarelli G, Touma EH, Williams SM, Clark AG. Haplotype diversity and linkage disequilibrium at human G6PD: recent origin of alleles that confer malarial resistance. Science. 2001;293:455-62.

14. Mombo LE, Ntoumi F, Bisseye C, Ossari S, Lu CY, Nagel RL, Krishnamoorthy R. Human genetic polymorphisms and asymptomatic Plasmodium 
falciparum malaria in Gabonese school children. Am J Trop Med Hyg. 2003; 68:186-90.

15. Guindo A, Fairhurst RM, Doumbo OK, Wellems TE, Diallo DA. X-linked G6PD deficiency protects hemizygous males but not heterozygous females against severe malaria. PLoS Med. 2007;4:e66.

16. Barid JK, Surjadjaja C. Consideration of ethics in primaquine therapy against malaria transmission. Trends Parasitol. 2011;27:11-6.

17. WHO. Strategy for malaria elimination in the greater Mekong subregion (2015-2030). Geneva: World Health Organization; 2015.

18. Malaria Policy Advisory Committee to the WHO. conclusions and recommendations of seventh biannual meeting (March 2015). Malar J. 2015;14:295

19. Matsuoka H, Wang J, Hirai M, Arai M, Yoshida S, Kobayashi T, Jalloh A, Lin K, Kawamoto F. Glucose-6-phosphate dehydrogenase (G6PD) mutations in Myanmar: G6PD Mahidol (487G>A) is the most common variant in the Myanmar population. J Hum Genet. 2004;49:544-7.

20. Nuchprayoon I, Louicharoen C, Charoenvej W. Glucose-6-phosphate dehydrogenase mutations in Mon and Burmese of southern Myanmar. J Hum Genet. 2008:53:48-54.

21. Bancone G, Chu CS, Somsakchaicharoen R, Chowwiwat N, Parker DM, Charunwatthana P, White NJ, Nosten FH. Characterization of G6PD genotypes and phenotypes on the northwestern Thailand-Myanmar border. PLoS One. 2014:9:e116063.

22. Li Q, Yang F, Liu R, Luo L, Yang Y, Zhang L, Liu H, Zhang W, Fan Z, Yang Z, Cui L, He Y. Prevalence and molecular characterization of glucose-6phosphate dehydrogenase deficiency at the China-Myanmar border. PLoS One. 2015;10:e0134593.

23. Oo NN, Bancone G, Maw LZ, Chowwiwat N, Bansil P, Domingo GJ, Htun MM, Thant KZ, Htut Y, Nosten F. Validation of G6PD point-of-care tests among healthy volunteers in Yangon, Myanmar. PLoS One. 2016;11:e0152304.

24. Kang JM, Cho PY, Moe M, Lee J, Jun H, Lee HW, Ahn SK, Kim TI, Park JH, Myint MK, Lin K, Kim TS, Na BK. Comparison of the diagnostic performance of microscopic examination with nested polymerase chain reaction for optimum malaria diagnosis in upper Myanmar. Malar J. 2017;16:119.

25. Peng Q, Li S, Ma K, Li W, Ma Q, He X, He Y, He T, Lu X. Large cohort screening of G6PD deficiency and the mutational spectrum in the Dongguan District in Southern China. PLoS One. 2015;10:e0120683.

26. Thein ST, Sudhinaraset M, Khin HS, McFarland W, Aung T. Who continues to stock oral artemisinin monotherapy? Results of a provider survey in Myanmar. Malar J. 2016;15:334.

27. Kotepui M, Uthaisar K, PhunPhuech B, Phiwklam N. Prevalence and hematological indicators of G6PD deficiency in malaria-infected patients. Infect Dis Poverty. 2016;5:36.

28. Khim N, Benedet C, Kim S, Kheng S, Siv S, Leang R, Lek S, Muth S, Chea N, Chuor CM, Duong S, Kerleguer A, Tor P, Chim P, Canier L, Witkowski B, Taylor WR, Ménard D. G6PD deficiency in Plasmodium falciparum and Plasmodium vivax malaria-infected Cambodian patients. Malar J. 2013;12:171.

29. Beutler E, Blume KG, Kaplan JC, Lohr GW, Ramot B, Valentine WN. International Committee for Standardization in Haematology: recommended methods for red-cell enzyme analysis. $\mathrm{Br} J$ Haematol. 1977:35:331-40

30. Van Noorden CJ, Vogels IM. A sensitive cytochemical staining method for glucose-6-phosphate dehydrogenase activity in individual erythrocytes. II. Further improvements of the staining procedure and some observations with glucose-6-phosphate dehydrogenase deficiency. Br J Haematol. 1985;60:57-63.

31. Beutler E, Mitchell M. Special modifications of the fluorescent screening method for glucose-6-phosphate dehydrogenase deficiency. Blood. 1968;32:816-8.

32. Ninfali P, Baronciani L, Bardoni A, Bresolin N. Muscle expression of glucose6-phosphate dehydrogenase deficiency in different variants. Clin Genet. 1995:48:232-7.

33. Au SW, Gover S, Lam VM, Adams MJ. Human glucose-6-phosphate dehydrogenase: the crystal structure reveals a structural NADP(+) molecule and provides insights into enzyme deficiency. Structure. 2000;8:293-303.

34. Huang Y, Choi MY, Au SW, Au DM, Lam VM, Engel PC. Purification and detailed study of two clinically different human glucose 6-phosphate dehydrogenase variants, G6PD (Plymouth) and G6PD (Mahidol): evidence for defective protein folding as the basis of disease. Mol Genet Metab. 2008;93:44-53.

35. Gómez-Manzo S, Terrón-Hernández J, De la Mora-De la Mora I, GonzálezValdez A, Marcial-Quino J, García-Torres I, Vanoye-Carlo A, López-Velázquez
G, Hernández-Alcántara G, Oria-Hernández J, Reyes-Vivas H, Enríquez-Flores S. The stability of G6PD is affected by mutations with different clinical phenotypes. Int J Mol Sci. 2014;15:21179-201.

36. Boonyuen U, Chamchoy K, Swangsri T, Saralamba N, Day NP, Imwong M. Detailed functional analysis of two clinical glucose-6-phosphate dehydrogenase (G6PD) variants, G6PDViangchan and G6PDViangchan +Mahidol: decreased stability and catalytic efficiency contribute to the clinical phenotype. Mol Genet Metab. 2016;118:84-91.

37. WHO Working Group. Glucose-6-phosphate dehydrogenase deficiency. Bull World Health Organ. 1989;67:601-11.

38. Bulliamy $T$, Luzzatto L, Hirono A, Beutler E. Hematologically important mutations: Glucose-6-phosphate dehydrogenase. Blood Cells Mols Dis. 1997;23:302-13

39. Kone AK, Sagara I, Thera MA, Dicko A, Guindo A, Diakite S, Kurantsin-Mills J, Djimde A, Walcourt A, Doumbo O. Plasmodium falciparum clearance with artemisinin-based combination therapy (ACT) in patients with glucose-6phosphate dehydrogenase deficiency in Mali. Malar J. 2010;9:332.

40. Carter N, Pamba A, Duparc S, Waitumbi JN. Frequency of glucose-6-phosphate dehydrogenase deficiency in malaria patients from six African countries enrolled in two randomized anti-malarial clinical trials. Malar J. 2011;10:241.

41. Na-Bangchang K, Sahasaeng W, Thanavibul A, Charoenlarp P, Karbwang J. Pharmacokinetics of primaquine in G6PD deficient and G6PD normal patients with vivax malaria. Trans R Soc Trop Med Hyg. 1994;88:220-2.

42. Matsuoka H, Nguon C, Kanbe T, Jalloh A, Sato H, Yoshida S, Hirai M, Arai M, Socheat D, Kawamoto F. Glucose-6-phosphate dehydrogenase (G6PD) mutations in Cambodia: G6PD Viangchan $(871 \mathrm{G}>\mathrm{A})$ is the most common variant in the Cambodian population. J Hum Genet. 2005;50:468-72.

43. Matsuoka H, Thuan DT, van Thien H, Kanbe T, Jalloh A, Hirai M, Arai M, Dung NT, Kawamoto F. Seven different glucose-6-phosphate dehydrogenase variants including a new variant distributed in lam Dong Province in southern Vietnam. Acta Med Okayama. 2007;61:213-9.

44. Nantakomol RP, Attakorn P, Day NPJ, White NJ, Imwong M. Evaluation of the phenotypic test and genetic analysis in the detection of glucose-6phosphate dehydrogenase deficiency Duangdao. Malar J. 2013;12:289.

45. Baird JK, Dewi M, Subekti D, Elyazar I, Satyagraha AW. Noninferiority of glucose6-phosphate dehydrogenase deficiency diagnosis by a point-of-care rapid test vs the laboratory fluorescent spot test demonstrated by copper inhibition in normal human red blood cells. Transl Res. 2015;165:677-88.

46. Bancone G, Chu CS, Chowwiwat N, Somsakchaicharoen R, Wilaisrisak P, Charunwatthana P, Bansil P, McGray S, Domingo GJ, Nosten FH. Suitability of capillary blood for quantitative assessment of G6PD activity and performances of G6PD point-of-care tests. Am J Trop Med Hyg. 2015;92:818-24.

47. Roca-Feltrer A, Khim N, Kim S, Chy S, Canier L, Kerleguer A, Tor P, Chuor CM, Kheng S, Siv S, Kachur PS, Taylor WR, Hwang J, Menard D. Field trial evaluation of the performances of point-of-care tests for screening G6PD deficiency in Cambodia. PLoS One. 2014;9:e116143.

48. Satyagraha AW, Sadhewa A, Elvira R, Elyazar I, Feriandika D, Antonjaya U, Oyong D, Subekti D, Rozi IE, Domingo GJ, Harahap AR, Baird JK. Assessment of point-of-care diagnostics for G6PD deficiency in malaria endemic rural eastern Indonesia. PLoS Negl Trop Dis. 2016;10:e0004457.

49. Peixoto HM, Brito MA, Romero GA, Monteiro WM, de Lacerda MV, de Oliveira MR. Cost-effectiveness analysis of rapid diagnostic tests for G6PD deficiency in patients with Plasmodium vivax malaria in the Brazilian Amazon. Malar J. 2016;15:82.

\section{Submit your next manuscript to BioMed Central and we will help you at every step:}

- We accept pre-submission inquiries

- Our selector tool helps you to find the most relevant journal

- We provide round the clock customer support

- Convenient online submission

- Thorough peer review

- Inclusion in PubMed and all major indexing services

- Maximum visibility for your research

Submit your manuscript at www.biomedcentral.com/submit
Biomed Central 